\title{
Effects of a treated sewage effluent on behavioural traits in Diamesa cinerella and Daphnia magna
}

\author{
Sara VILLA,${ }^{*}$ Valeria DI NICA, ${ }^{1}$ Francesco BELLAMOLI,${ }^{3}$ Tanita PESCATORE, ${ }^{2}$ Claudia FERRARIO,${ }^{1}$ \\ Antonio FINIZIO, ${ }^{1}$ Valeria LENCIONI ${ }^{3}$ \\ ${ }^{1}$ Department of Earth and Environmental Sciences, University of Milano Bicocca, Piazza della Scienza 1, 20126 Milan; ${ }^{2}$ Water Research \\ Institute, National Research Council (IRSA-CNR), Via Salaria km 29.300, Monterotondo, 00015 Rome; ${ }^{3}$ Section of Invertebrate Zoology \\ and Hydrobiology, MUSE - Museo delle Scienze, Corso del Lavoro e della Scienza 3, 38122 Trento, Italy \\ *Corresponding author: sara.villa@unimib.it
}

\begin{abstract}
Recently, the use of Daphnia magna has been proposed in real-time biomonitoring programmes as an early warning system for evaluating the effluent quality of sewage treatment plants (STPs). These systems are based on recording behavioural changes in the test organism resulting from the stress caused by the effluents. Indeed, altered behavioural signals could be induced at sublethal concentrations that are significantly lower than the corresponding EC50. However, at present, it is unknown whether the sensitivity of D. magna can be representative of that of other aquatic organisms, particularly benthic macroinvertebrates. An experiment was designed to verify whether D. magna can be employed in biomonitoring programmes for STPs located in alpine areas as a surrogate of species which are adapted to cold freshwater ecosystems. The responses of survival and behaviour alteration to exposure to the effluent of the Tonale Pass plant (Trentino, Italian Alps, $46^{\circ} \mathrm{N}, 10^{\circ} \mathrm{E} ; 1799 \mathrm{~m}$ asl) were compared in a laboratory population of D. magna and a wild population of the chironomid Diamesa cinerella. Larvae of this species were collected from the Vermigliana stream 50 metres upstream of the effluent input. Both organisms were exposed for 24 and $48 \mathrm{~h}$ to the effluent as it is and to three dilutions (STP/10, STP/100, STP/1000). The mortality rate and behavioural responses (using video tracking systems) were recorded. No significant mortality or change in behaviour was observed in the two species when exposed to the undiluted effluent. Exposure to serial dilutions of the treated effluent did not affect the survival of either species but notably altered their behaviour at both exposure times (e.g., the time spent in activity in $D$. magna and the average speed of movement and the cumulative distance travelled in both), especially when exposed to the STP/10 effluent. Overall, the findings of this study emphasize that even though $D$. magna and $D$. cinerella use different behavioural strategies to cope with adverse environmental conditions, their overall sensitivity to treated effluents is similar. Accordingly, the use of $D$. magna in biological early warning systems protocols seems to also be sufficiently protective for local, cold-adapted species of alpine freshwater ecosystems.
\end{abstract}

Key words: Sewage treatment plants; Chironomidae; Daphniidae; behavioural changes; video tracking; alpine streams.

Contributions: FB,CF, performed the toxicological tests, optimized workflows and processed the parameters of the video tracking system; VDN, collaborated on the processing of the data and on the toxicological and statistical analyses; TP, performed the video tracking analysis. SV,VL, conceived and designed the experiments; AF, VDN,SV, wrote the manuscript, and the other authors revised the paper.

Received: January 2018. Accepted: April 2018.

This paper was presented at the $20^{\text {th }}$ International Symposium on Chironomidae, Trento, Italy, 2-8 July 2017. Session: Toxicology and Adaptive Biology.

\section{INTRODUCTION}

Water contamination has become one of the major threats to the survival of living organisms in aquatic systems (Reid et al., 2013). Effluents from sewage treatment plants (STPs) are recognized as one of the main routes of entry of emerging contaminants, such as pharmaceuticals and personal care products, into the aquatic environment (European Commission, 2016). The environmental regulations of the European Union (EU) aim to reduce the pol- lution of surface water caused by STPs (Directive 2000/60/EC). Such reductions require the EU member states to ensure that the discharge of wastewater and the effects of this discharge are continuously monitored (Farré et al., 2001). In this regard, the protection of the receiving waters is the primary goal of municipal STPs. Of particular relevance is the control of the quality of the STP effluents discharged into alpine aquatic systems because they are intrinsically fragile (Kaul, 1993) and serve as a water supply to surrounding areas (Alpine Convention, 2009). Alpine environments are threatened by atmospher- 
ically transported pollutants (Villa et al., 2014; Chiogna et al., 2016; Ferrario et al., 2017; Morselli et al., 2018), and discharge from STPs further contributes to alpine freshwater pollution. For instance, Mandaric and co-authors (2017) measured the presence of pharmaceuticals and personal care product residues downstream of STPs in different alpine rivers.

As is often noted (Metcalf and Eddy, 2003; Movahedian et al., 2005; Teodorović et al., 2009), physical and chemical parameters alone are not sufficient for obtaining reliable information about the toxicity of treated effluents. For this reason, toxicity tests are performed in combination with routine physical and chemical analysis. Indeed, the direct toxicity assessment of STP effluents can contribute to maintaining the good ecological status of water bodies. One of the most commonly used bioassays for monitoring the toxicity of effluents is the acute toxicity test performed with Daphnia magna (Koçbaş and Oral, 2015). More recently, the use of real time biomonitoring for the surveillance of STP effluent quality has been proposed (Allan et al., 2006; Jeong et al., 2008, 2014; Häder and Erzinger, 2017a, 2017b). This approach allows the continuous determination of the integrated toxicity of water and has the advantage that the identification of the plethora of water pollutants that are present in wastewater effluents becomes unnecessary (Chen et al., 2013). Real time biomonitoring frequently use behaviour as an endpoint, which provides a visual and thus measurable response at the whole-organism level (Gerhardt, 1995). In addition, behavioural changes are recognized as more sensitive endpoints than the traditional ones (i.e., mortality or immobilization), as altered behavioural signals can be induced at even sublethal concentrations (Gerhardt, 2007; Hellou et al., 2008). Daphnia magna is again the most frequently used organism in these biomonitoring activities. Indeed, when this organism faces a change in water quality or a toxic condition, its behaviour markedly changes. For this reason, many regulations consider this organism as representative of the invertebrates in aquatic ecosystems (European Commission, 2002, 2003, 2006). Nevertheless, this assumption will not always hold true (Wogram and Liess, 2001; Maltby et al., 2005; WibergLarsen et al., 2016). Indeed, the sensitivity of macroinvertebrate species can be related to ecological traits (e.g., respiration type and temperature and current velocity preference, which are all related to skin thickness and permeability) (Wiberg-Larsen et al., 2016). For instance, according to biological trait approaches, it has been demonstrated that Chironomus spp. (Diptera: Chironomidae, Chironominae subfamily) are more sensitive to some categories of pollutants, such as organochlorine and neonicotinoid pesticides, than D. magna (Rico et al., 2015). It is unknown whether chironomids are also more sensitive than daphnids towards other aquatic contaminants that can be found in STP effluents, such as pharmaceuticals and per- sonal care products. Differences in sensitivity could be exacerbated in the extreme conditions of cold ecosystems, such as in alpine environments, where cold-adapted species have evolved traits that could influence their sensitivity towards toxicants (Lencioni, 2018).

In this context, the aim of this work was to analyse and compare the sensitivity of a laboratory population of D. magna and a wild population of the alpine chironomid Diamesa cinerella (Diamesinae subfamily) when exposed to different dilutions of the effluent from the Tonale Pass STP in the Italian Alps (NE Italy). The Diamesa genus prevails in headwaters and is often associated with pristine environments (Lencioni et al., 2012; Niedrist and Fuereder, 2016). Differences in mortality and behaviour between the two species were investigated to verify whether $D$. magna could be utilized in toxicity and biomonitoring programmes for alpine streams as a surrogate of the local wild species. The utilization of D. magna might be very useful, considering that even at high altitudes in mountain valleys strongly affected by tourism, pharmaceuticals and personal care products in surface waters are an emerging environmental problem (Mandaric et al., 2017).

\section{METHODS}

\section{Effluent sampling}

The effluent was collected from the STP of the Tonale Pass, which is located at $1799 \mathrm{~m}$ a.s.l. on the banks of the Vermigliana stream, a tributary of the Noce river, in the Italian Alps (http://adep.heidix.net/plant.html?PT; Trentino, $\mathrm{NE}$ Italy; $\left.46^{\circ} \mathrm{N}, 10^{\circ} \mathrm{E}\right)$. The STP collects wastewater from an area of strong tourism, which occurs both in winter and mid-summer. It is designed to serve 10,000 equivalent inhabitants and implements conventional treatments (oxidation, secondary sedimentation). The main technical information regarding the treatment processes can be downloaded from the "Agenzia per la Depurazione della Provincia di Trento" webpage, at https://adep.provincia. tn.it/Agenzia-per-la-Depurazione-ADEP.

The effluent was sampled on 6 March 2017, the day after the end of the carnival holidays. All samples were collected in sterile graduated water bottles in polypropylene (PP) (from LP Italiana, Milan, Italy), kept refrigerated during transport and subsequently stored at $-20^{\circ} \mathrm{C}$.

\section{Behavioural tests}

\section{Daphnia magna experimental plan}

The tested organisms originated from a single clone of D. magna Straus taken from the Istituto Superiore di Sanità (Rome, Italy) and were cultivated as reported elsewhere (Ferrario et al., 2018). Five 5-day-old individuals 
were exposed to four different dilutions (STP, STP/10, $\mathrm{STP} / 100, \mathrm{STP} / 1000$ ) of the STP effluent in $50 \mathrm{ml}$ bottles for $48 \mathrm{~h}$. The test solutions were renewed $24 \mathrm{~h}$ after the beginning of the experiment. Tests were performed with four replicates per treatment and four negative controls. The specimens were not fed during the tests. At the end of each exposure time, the daphnids were transferred to the designed arena, and the swimming activity of the organisms was recorded as described below.

\section{Diamesa cinerella experimental plan}

As model animals, IV instar larvae of Diamesa belonging to the cinerella group of species, called $D$. cinerella in the text, were collected on 6 March 2017 using a $30 \times 30 \mathrm{~cm}$ pond net (mesh size $100 \mu \mathrm{m}$ ) (Scubla Snc, Italy) in the Vermigliana stream at $1799 \mathrm{~m}$ asl and 50 metres upstream of the effluent input. The larvae were sorted in the field with tweezers, transferred to plastic bottles filled with stream water and transported to the laboratory in a cooling bag. Species confirmation was performed within $24 \mathrm{~h}$ of sampling using a stereomicroscope (MZ 7.5; Leica Microsystems, Germany; 50×) according to Rossaro and Lencioni (2015). The animals were maintained in $1 \mathrm{~L}$ glass aquaria with stream water in a thermostatic chamber (ISCO, model FTD250-plus; Teledyne Isco Inc., Lincoln, NE, USA) at $4^{\circ} \mathrm{C}$ and under aeration to maintain the dissolved oxygen at higher than $80 \%$ saturation. The incubation temperature $\left(4^{\circ} \mathrm{C}\right)$ approximated the water temperature measured in the stream with a multiparametric probe (Hydrolab Quanta, Hydrolab Corporation ${ }^{\circledR}$, TX, USA). To acclimate the larvae to the exposure conditions, $24 \mathrm{~h}$ prior to each experiment, randomly selected IV instar larvae were removed from the rearing aquarium and transferred to a $500 \mathrm{~mL}$ beaker (approximately 40 larvae per beaker) containing $200 \mathrm{~mL}$ of hard reconstituted water (HRW) according to Lencioni et al. (2016). During acclimatization and exposure, the larvae were kept at $4 \pm 1{ }^{\circ} \mathrm{C}$ without light and food but with aeration.

Six larvae were exposed for $48 \mathrm{~h}$ to four serial dilutions of STP effluent as described above. Tests were performed with three replicates per treatment and negative controls. The test solutions were renewed every $24 \mathrm{~h}$. Videos were taken after 24 and $48 \mathrm{~h}$ of exposure.

After $24 \mathrm{~h}$, the control and treated larvae and their exposure solution were poured into a $50 \mathrm{~mL}$ beaker on a worktable in a climate-controlled room at $4 \pm 0.1^{\circ} \mathrm{C}$, where videos were taken for 120 - $180 \mathrm{~s}$ with a digital HD camera (Raspberry Pi 3 with Camera Module v2) at high resolution $(1920 \times 1080$ pixels $)$ approximately $10 \mathrm{~cm}$ from the bottom of the beaker. During the video recording time, the water temperature changed within a range of +0.1 to $+0.3^{\circ} \mathrm{C}$, as measured using a portable thermometer (Koch $13211 ; \pm 1^{\circ} \mathrm{C}$ ).

\section{Daphnia magna video tracking analysis}

Video tracking analyses were carried out for all the living daphnids after 24 and $48 \mathrm{~h}$ of exposure. At the end of each exposure time, the daphnids from each bottle were transferred to the designed arena $(80 \mathrm{~mm} \times 75 \mathrm{~mm} \times 5$ $\mathrm{mm}$ ), with each containing 5 daphnids and $30 \mathrm{~mL}$ of the test solution. Each arena was placed in front of a light panel and, after 30 min of acclimatization, video recordings were taken. The activity of five individuals was tracked contemporaneously for 10 minutes. The 1080p full $\mathrm{HD}$ videos acquired were converted into avi files and partitioned into ten sections of $30 \mathrm{~s}$ each with FFMPEG (http://www.ffmpeg.org) so that all videos contained 900 frames $\left(30\right.$ frames $\left.\mathrm{s}^{-1}\right)$. Subsequently, the mini-videos were analysed using the software LoliTrack v.4 (Loligo Systems, Tjele, Denmark). By adapting the RGB thresholds, the LoliTrack v.4 software identifies all pixels similarly coloured in the image as objects in contrast with respect to the background. In this way, the software tracks the activities of daphnids (objects) in contrast to the water by assigning an $\mathrm{X}, \mathrm{Y}$ position to their centres.

\section{Diamesa cinerella video tracking analysis}

The videos were analysed using the software ImageJ (http://imagej.nih.gov/ij/), a public domain Java image processing program. The plugin and a detailed description of animal tracking can be found at http://www.phage. $\mathrm{dk} /$ plugins/wrmtrck.html (Brooks et al., 2016). The software was optimized/calibrated to monitor three different behavioural endpoints for the $D$. cinerella larvae (for details, refer to Villa et al., 2018).

Each original video was converted into an avi file and was partitioned into five sections of $30 \mathrm{~s}$ each with FFMPEG ( 900 frames; 30 frames s ${ }^{-1}$ ). Subsequently, the minivideos were processed with ImageJ, and the data were converted from pixels to $\mathrm{mm}$ and from pixels $\mathrm{s}^{1}$ to $\mathrm{mm} \mathrm{s}^{-1}$. In ImageJ, the same length was measured using the straight line tool: a line was drawn from one edge of the backer to the other, and the length was measured in pixels (Brooks et al., 2016).

\section{Behavioural endpoints}

Daphnia magna and Diamesia cinerella are different in their bio-ecological traits as they belong to pelagic and benthic group of organisms, respectively. For this reason, there was a need to use two different video tracking systems which were specifically developed for these typologies of organisms. The two utilized software partially differ in the number and typologies of measured parameters. However, for some outputs, they are equivalent and have comparable meanings.

On this basis in our study, four behavioural endpoints were monitored: 
- average speed, which is the movement velocity calculated frame by frame as the length/time ratio $\left(\mathrm{mm} \mathrm{s}^{-1}\right)$, where the length is the sum of the lengths of all movement vectors between frames given track;

- distance moved, which is the sum of the distances covered by the animal from start to finish in the analysed video;

- activity, which is the time of activity (\%). The lowest threshold for activity is defined as the activity threshold (pixels), e.g., if the object moves a distance larger than this minimum distance, it is scored as active;

- BBps, or the number of times that the organism changes its shape in a second, which is calculated using the angle (the direction in which the organism is pointing, between 0 and $180^{\circ}$ ) during all video frames.

Changes in the average speed and distance moved were measured in both organisms, the percent of activity was monitored in D. magna and BBps was monitored in D. cinerella.

\section{Statistical analysis}

Mortality differences were determined by using analysis of variance followed by Dunnett's test for the comparison of treated animals respect to the controls. Comparison among all exposure conditions were assessed with Tukey's test (Gary et al., 1990). Differences were considered significant at $\mathrm{P} \leq 0.05$. Behavioural results were analysed using Student's $t$-test to detect statistically significant differences for each treatment group with respect to the control and between each comparable endpoint (AvgSpeed and Distance) for the two tested organisms at each exposure time (24 and $48 \mathrm{~h}$ ). The existence of outliers was investigated using the Grubbs test with the XLSTAT statistical software (Addinsoft 1995-2017). This test allows to determine whether one of the obtained values is a significant outlier from the rest, and then expunged from the dataset. Statistical tests were performed using R-project software package (R Core Team, 2017). Statistical significance is indicated by asterisks: $* * * * \mathrm{P}<0.0001$; $* * * \mathrm{P}<0.001 ; * * \mathrm{P}<0.01 ; * \mathrm{P}<0.05$.

\section{RESULTS}

\section{Mortality}

For both species, no mortality was observed in the controls, indicating the validity of the test (Tab. SI-1 and Tab. SI-2). Tabs. SI-1 and SI also report the numbers of dead organisms measured for different effluent dilutions after 24 and $48 \mathrm{~h}$ of exposure in D. magna and $D$. cinerella, respectively. In D. magna, no mortality was detected in the undiluted samples of effluents (STP), whereas a progressive increase in mortality was observed with increasing dilutions and exposure time: 2 and 3 organisms after $24 \mathrm{~h}$ in the STP/100 and STP/1000 effluent and 1,3 and 4 after $48 \mathrm{~h}$ in the STP/10, STP/100 and STP/1000 solutions, respectively. In contrast, no mortality was detected in $D$. cinerella (with a partial exception of 1 organism dead at the highest dilution after $24 \mathrm{~h}$ ).

\section{Behavioural tests}

The average speed and distance moved were quantified in both species, whereas the activity and BBps were specifically measured in $D$. magna and $D$. cinerella, respectively. All measured data are reported in detail in the Supporting Information section (Tab. SI-1 and SI-2). For both tested species, the relative standard deviations of controls and treated samples are comparable; the observed variability in controls are within the range observed by Villa et al., 2018 and Ferrario et al., 2018. However, in $D$. cinerella, the distance moved appeared to be more scattered, as suggested by the high RDS values both in the controls and exposed specimens. The higher variability in D. cinerella is mainly due to the heterogeneity in the individuals, which were collected from natural populations, whereas the D. magna specimens were obtained from a single clone cultured in the laboratory. However, we note that from an ecological point of view, higher variability in responses could allow better adaptation and survival strategies for the species.

Fig. 1 (A, B, C, D) shows deviations from the controls for the average speed and distance moved at different STP dilutions and times of exposure. After 24 and $48 \mathrm{~h}$ of exposure, both species showed the greatest behavioural deviations from the controls when exposed to diluted effluents.

In D. magna, after $24 \mathrm{~h}$ of exposure, the average speed and distance moved (Fig. $1 \mathrm{~A}, \mathrm{C})$ significantly increased under the STP/10 dilution $(\mathrm{P}<0.01)$, whereas under the $\mathrm{STP} / 100$ dilution, the organisms showed only a significant increase in the average speed $(\mathrm{P}<0.05)$. Finally, no differences were observed among specimens exposed to STP and the STP/1000 dilutions compared to the controls.

After $48 \mathrm{~h}$ (Fig. $1 \mathrm{~B}, \mathrm{D})$, the average speed still significantly increased only under the STP/10 dilution $(\mathrm{P}<0.01)$. In contrast, the distance moved significantly decreased under the STP/100 and STP/1000 dilutions $(\mathrm{P}<0.05)$, whereas the organisms returned to the level of control when exposed to the STP/10 dilution.

In D. cinerella, the average speed parameter did not seem to be influenced during all the exposure period (Fig. $1 \mathrm{~A}, \mathrm{~B}$ ) (with the partial exception of STP/1000 at $24 \mathrm{~h}$, at which a reduction in the swimming speed was recorded; $\mathrm{P}<0.05$ ). The distance moved (Fig. $1 \mathrm{C}, \mathrm{D}$ ) significantly declined for both exposure periods and all STP dilutions, with a recovery under the STP/1000 dilution after $48 \mathrm{~h}$.

Fig. 2 shows the measured changes from the controls 
of the active time and BBps parameters for D. magna and $D$. cinerella, respectively. Compared to the controls, after $24 \mathrm{~h}$ of exposure, D. magna showed an increase in the active time under the STP/10 and STP/1000 dilutions (Fig. 2A). In contrast, a significant reduction in this behavioural endpoint was observed after $48 \mathrm{~h}$ in all the STP dilutions (Fig. 2B), whereas an increase in the active time was measured in organisms exposed to undiluted STP. In D. cinerella, no significant changes in BBps were observed during either of the exposure periods, with the exception of the organisms exposed to the highest STP dilution (STP/1000) after $48 \mathrm{~h}$ of exposure, in which an increase in the BBps value was observed.

\section{DISCUSSION}

Whole effluent toxicity (WET) tests were formalized 'to identify, characterize, and eliminate toxic effects of discharges on aquatic resources' (Chapman, 2000), and biological early warning systems (BEWS) have been con- sidered to be a powerful tool for evaluating the WET. According to Jeong and co-authors (2014), BEWS have been diversified through the employment of various test organisms, such as algae, fish and water fleas, and are generally based on acute toxicity tests (Baldwin et al., 1994; Benecke et al., 1982; Hendriks and Stouten, 1993). In BEWS protocols, D. magna is widely used because of its high sensitivity to pollutants and rapid behavioural responses when exposed to a change in water quality (Jeong et al., 2014). However, several studies have clearly indicated that acute toxicity (single or in mixtures, such as effluents) may change considerably among species (Wogram and Liess, 2001; Maltby et al., 2005; Rubach et al., 2010) depending on the toxicological mode of action of the chemicals (Escher and Hermens, 2002) and metabolic traits of the species (Nyman et al., 2014). To our knowledge, there have been few studies comparing sensitivity in terms of the behavioural responses to chemicals of different species from different environments.

An inverse concentration-response relationship be-
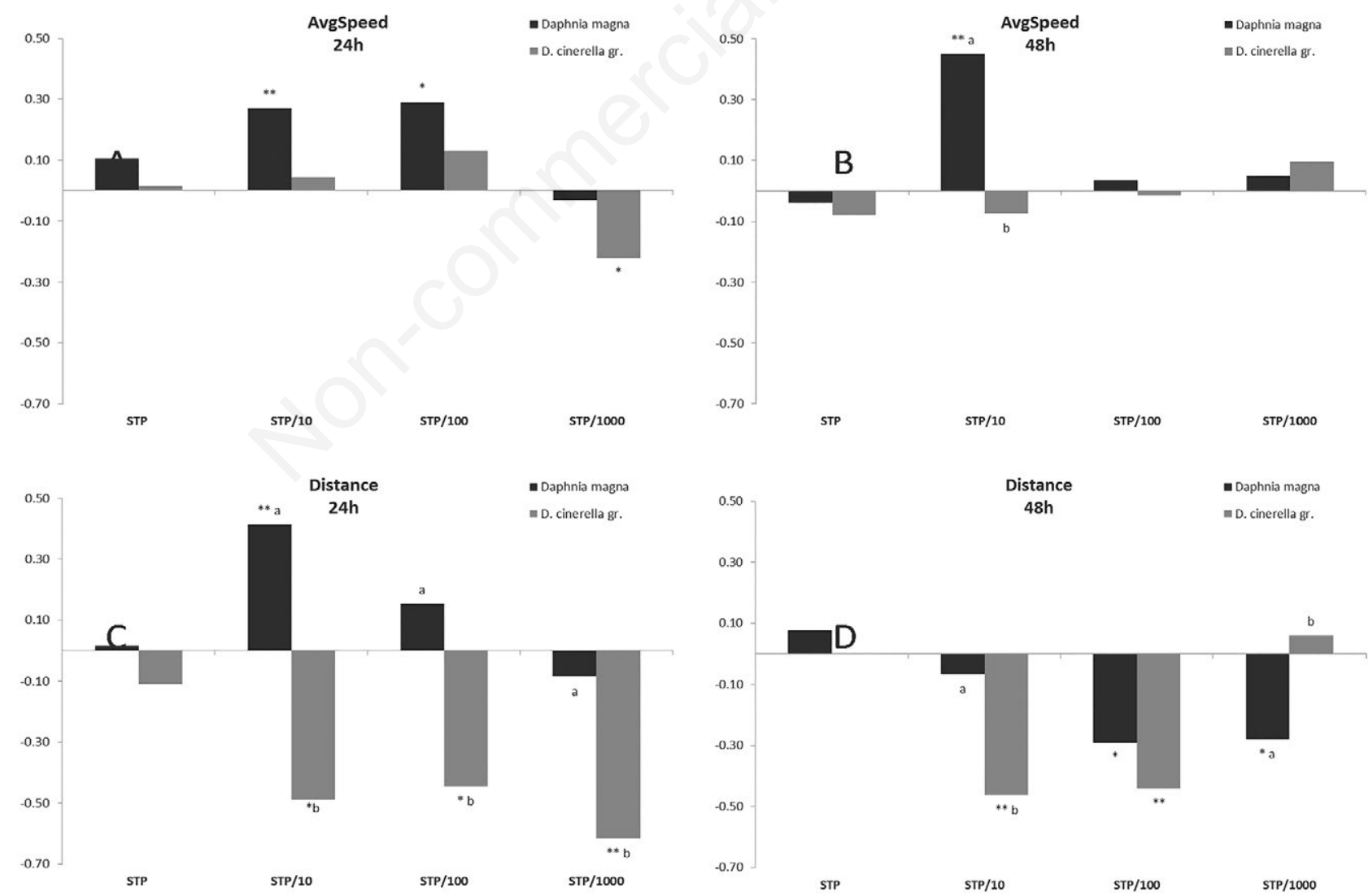

Fig. 1. Histograms of increasing/decreasing effects on behavioural parameters (average speed after $24 \mathrm{~h}(\mathrm{~A})$ and $48 \mathrm{~h}$ (B) of exposure and distance moved after $24 \mathrm{~h}(\mathrm{C})$ and $48 \mathrm{~h}(\mathrm{D})$ of exposure) in D. magna and D. cinerella exposed to different STP dilutions. Asterisks indicate significant difference from the control $(* * \mathrm{P}<0.01 ; * \mathrm{P}<0.05)$. Different letters indicate a significant difference between the two tested organisms $(\mathrm{P}<0.05)$. 
tween mortality and the increasing dilution of STP effluents and exposure time was observed in D. magna. However, this result was not statistically significant. Significant changes in swimming capabilities (activity time, distance moved, and velocity) were measured in $D$. magna when exposed to different STP effluent dilutions, indicating an overall condition of stress. The highest stress was measured under the STP/10 dilution according to all behavioural parameters investigated. In contrast, undiluted STP output seemed to not particularly influence swimming parameters (with the exception of active time after $48 \mathrm{~h}$ of exposure), whereas the measured changes were random for STP/100 and STP/1000. Under the STP/10 dilution, the average speed significantly increased during both exposure periods, whereas under STP/100, a significant increase was measured only after $24 \mathrm{~h}$ of exposure, with a recovery after $48 \mathrm{~h}$. Such increases in the average speed has been associated with an avoidance mechanism, which is the escape from contamination or from undesirable abiotic conditions (Wolf et al., 1998). In contrast to the average speed, changes in the distance moved and active time showed a different trend. Indeed, after $24 \mathrm{~h}$ of exposure, both parameters significantly increased under STP/10 (in addition to the active time also under STP/1000) but decreased after $48 \mathrm{~h}$. The explanation for these opposite responses is not obvious. Recently, Ferrario and co-authors (2018) highlighted a reduction in the active time and partially in the distance moved in $D$. magna specimens exposed to different concentrations of the insecticide chlorpyriphos after $48 \mathrm{~h}$ of exposure; the authors suggested that the reduction in both parameters was due to the loss of energy spent by organisms to activate detoxifying enzymes and the mechanism of avoidance (increased average speed). Analogously, we hypothesize that the organisms spent part of their available energy on activating these mechanisms of defence.

The exposure of $D$. cinerella to diluted STP effluents caused some behavioural alterations. In contrast, undiluted samples did not affect its behaviour. The most affected parameter seemed to be the distance covered, which showed a significant reduction in all the diluted STP effluent samples both at 24 and $48 \mathrm{~h}$ of exposure. Variation in the average speed and BBps was randomly observed (STP/1000 after 24 and $48 \mathrm{~h}$ for the average
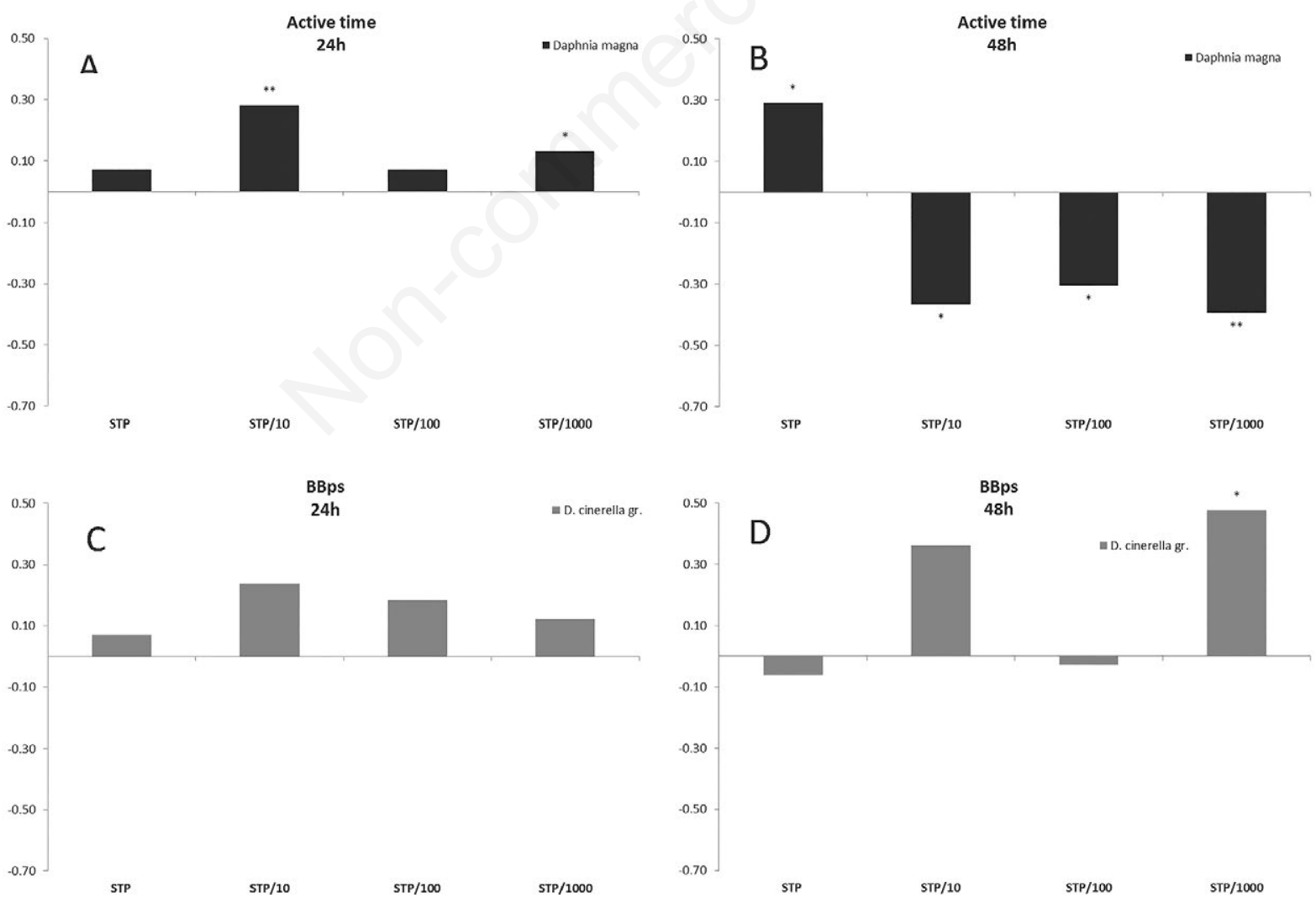

Fig. 2. Histograms of increasing/decreasing effects on active time (in D. magna) after $24 \mathrm{~h}$ (A) and $48 \mathrm{~h}$ (B) of exposure and BBps (= body bends/sec) (in D. cinerella) after $24 \mathrm{~h}(\mathrm{C})$ and $48 \mathrm{~h}$ (D) of exposure when the organisms were exposed to different STP dilutions. Asterisks indicate a significant difference from the control $(* * \mathrm{P}<0.01 ; * \mathrm{P}<0.05)$. 
speed and BBps, respectively). To the best of our knowledge, there have been no previous studies investigating the behavioural changes induced by contaminants in $D$. cinerella. Very recently, Villa and co-authors (2018) developed an experimental protocol to investigate behavioural changes in $D$. zernyi gr. larvae exposed to several pharmaceuticals and plant protection products with different toxicological modes of action. The exposed organisms were sensitive to chemical stressors; indeed, behavioural alterations were measured at concentrations below the LOECs (lowest observed effect concentrations) of the investigated compounds. Also, in this study, the most affected behavioural parameter was the distance moved, which showed a general trend of reduction. Our study confirms this evidence and indicates that this parameter is the most relevant to be included in behavioural studies for the genus Diamesa. As for D. magna, the reduction in the distance cumulatively travelled by Diamesa can be related to the attempt of organisms to mitigate changed conditions. The effects of changes in external conditions, such as the burden imposed by toxic compounds or changes in the habitat conditions, probably induce stress such that the energy that is usually destined for normal functions (growth, reproduction, and locomotion) must be used to restore the imbalance (stress response) by activating antioxidant and detoxifying enzymes (Untersteiner et al., 2003; Binelli et al., 2011).

\section{Comparison between D. magna and D. cinerella}

Neither organism was particularly sensitive (in terms of mortality) to the undiluted and diluted effluents. Slightly higher mortality (though not statistically significant) was observed in D. magna. This is in line with results in the literature that indicate that chironomids are less sensitive than daphnids in their response to various toxicants (Cowgill and Williams, 1989). In addition, the undiluted STP samples did not cause any variations in the behaviour of either species after 24 or $48 \mathrm{~h}$, whereas the diluted effluents seemed to produce significant behaviour alterations in both species. This apparently anomalous response pattern (decrease of effects with increasing effluent concentrations) has been already reported in literature and could be attributed to changes in abiotic conditions (e.g., hardness, $\mathrm{pH}$ ) with dilutions (Environmental Protection Agency, 2000). For instance, changes in $\mathrm{pH}$ can influence the bioavailability and toxicity of chemical constituents, such as some metals (e.g., $\mathrm{Cu}, \mathrm{Zn})$.

Specifically, the two species showed significant behavioural changes when exposed to the STP/10 dilution samples, in which $D$. magna seemed to be more sensitive than $D$. cinerella, as all three behavioural parameters were significantly affected by this dilution.

The two organisms presented differences in terms of behavioural responses. In D. magna, the most influenced swimming parameter was the average speed, which significantly increased even after $48 \mathrm{~h}$ of exposure under the $\mathrm{STP} / 10$ dilution. In contrast, $D$. cinerella experienced a significant decrease in the distance moved. It is very difficult to explain the bases of these differences. It is most likely that they derive from the different strategies used by the two organisms to cope with unfavourable environments. Daphnia magna is a pelagic organism, and perhaps the easiest strategy for reacting to stress is the avoidance mechanism, which results in swimming away from an unfavourable condition; as previously described, avoidance has been associated with an increase in the average speed. In contrast, in benthic organisms such as $D$. cinerella, the strategy is to activate the adaption mechanisms that involve antioxidant and detoxifying enzymes (Untersteiner et al., 2003; Binelli et al., 2011). This leads to an energy expenditure that reduces the moved distance of the organisms. At this level of study, the ecological consequences of a reduction in the distance moved cannot be easily understood; however, changes in the behaviour of a key species such as $D$. cinerella can lead to unpredictable effects at higher levels of the food chain. Surprisingly, the undiluted effluent did not have any observable effects on the two tested species, while the greatest effect was recorded in both species when they were exposed to the STP/10 effluent. Similar results have been observed in Gammarus pulex and Chironomus riparius (Lange et al., 2006; Azevedo-Pereira et al., 2011).

As previously reported a possible explanation could be attributed to changes in abiotic conditions (e.g., hardness, $\mathrm{pH}$, or increased bioavailability of toxic compounds) (Environmental Protection Agency, 2000). However, further investigations are needed in order to understand these results.

The lesson learned in this study is that the two species use different behavioural strategies to react to the presence of adverse environmental conditions but that their overall sensitivity is similar. Even if the discharge of effluents from an alpine STP do not cause significant mortality events, it has the potential to affect the behaviour of both species. Consequently, the use of D. magna as a WET test species could also be sufficiently protective for the resident species of alpine freshwater ecosystems. The use of D. magna might be advantageous in biomonitoring programmes in terms of the ease of handling and cost effectiveness of the culture conditions in the laboratory for D. magna.

\section{ACKNOWLEDGEMENTS}

We are grateful to Alessandra Franceschini and Francesca Paoli for their help with the field and laboratory work.

This work was supported by the "Cassa di Risparmio di Trento e Rovereto Foundation" (CARITRO n. Rif. Int.: 2015.0199; 2015-2018), the MUSE Museo delle Scienze 
of Trento, and the University of Milano-Bicocca. Tanita Pescatore received a grant from the 'Torno subito' training programme of the ESF (European Social Fund programme).

\section{REFERENCES}

Allan IJ, Vrana B, Greenwood R, Mills GA, Roig B, Gonzalez C, 2006. A "toolbox" for biological and chemical monitoring requirements for the European Union's Water Framework Directive. Talanta 69:302-322.

Alpine Convention, 2009. Water and water management issues. Report on the State of the Alps. Permanent Secretariat of the Alpine Convention, Bozen: 56 pp.

Baldwin IG, Harman MMI, Neville DA, 1994. Performance characteristics of a fish monitor for detection of toxic substances. Water Res. 28:2191-2199.

Benecke G, Falke W, Schmidt C, 1982. Use of algal fluorescence for an automated biological monitoring system. Bull. Environ. Contam. Toxicol. 28:385-395.

Binelli A, Parolini M, Pedriali A, Provini A, 2011. Antioxidant activity in the zebra mussel (Dreissena polymorpha) in response to triclosan exposure. Water Air Soil Poll. 217:421-430.

Boyd GR, Reemtsma H, Grimm DA, Mitra S, 2003. Pharmaceuticals and personal care products (PPCPs) in surface and treated waters of Louisiana, US and Ontario, Canada. Sci. Total Environ. 311:135-149.

Brooks DS, Vishal K, Kawakami J, Bouyain S, Geisbrecht ER, 2016. Optimization of wrMTrck to monitor Drosophila larval locomotor activity. J. Insect Physiol. 93:11-17.

Chapman GA, Denton DL, Lazorchak JM, 1995. Short-term methods for estimating the chronic toxicity of effluents and receiving waters to west coast marine and estuarine organisms. USEPA Report No. EPA/600/R-95/136.

Chapman PM, 2000. Whole effluent toxicity testing - usefulness, level of protection and risk assessment. Environ. Toxicol. Chem. 19:3-13.

Chen LL, Fu X, Zhang G, Zeng Y, Ren Z, 2013. Influences of temperature, $\mathrm{pH}$ and turbidity on the behavioural responses of Daphnia magna and Japanese Medaka (Oryzias latipes) in the biomonitor. Procedia Environ. Sci.13:80-86.

Chiogna G, Majone B, Cano Paoli K, Diamantini E, Stella E, Mallucci S, Lencioni V, Zandonai F, Bellin A. 2016. A review of hydrological and chemical stressors in the Adige catchment and its ecological status. Sci. Total Environ. 540:429-443.

Cowgill UM, Williams LR, 1989. Aquatic toxicology and hazard assessment. American Society for Testing and Materials, Philadelphia: 444 pp.

Colwill RM, Creton R, 2011. Imaging escape and avoidance behavior in zebrafish larvae. Rev. Neurosci. 22:63-73.

Cristale J, Lacorte S, 2015. PBDEs versus NBFR in wastewater treatment plants: occurrence and partitioning in water and sludge. AIMS Environ. Sci. 2:33-546.

Duquesne S, Liess M, 2010. Indirect effects of pesticides on mosquito larvae via alterations of community structure. Isr. J. Ecol. Evol. 56:433-447.

Duquesne S, Küster E, 2010, Biochemical, metabolic, and behavioural responses and recovery of Daphnia magna after exposure to an organophosphate. Ecotoxicol. Environ. Saf. 73:353-359.

Environmental Protection Agency, 2000. Method guidance and recommendations for whole effluent toxicity (WET) testing (40 CFR Part 136). Office of Water, U.S. Environmental Protection Agency, Washington.

European commission, 1998. Commission Directive 98/15/EC of 27 February 1998 amending Council Directive 91/271/EEC with respect to certain requirements established in Annex I thereof.

European Commission, 2000. Directive 2000/60/EC of the European Parliament and of the Council of 23 October 2000 establishing a framework for Community action in the field of water policy.

European Commission, 2002. Guidance document on aquatic ecotoxicology in the context of the directive 91/414/EEC, Rep. No. Sanco/3268/2001 rev.4 (final). Brussels, Belgium. Available from: http://ec.europa.eu/food/plant/protection/ evaluation/guidance/wrkdoc10_en.pdf.

European Commission, 2003. Technical Guidance Document (TGD) on Risk Assessment of Chemical Substances. European Chemical Bureau, Joint Research Centre, EUR20418EN/2.

European Commission, 2006. Regulation (EC) No 1907/2006 of the European Parliament and of the Council of 18 December 2006 concerning the registration, evaluation, authorisation and restriction of chemicals (REACH), establishing a European Chemicals Agency, amending Directive 1999/45/EC and repealing Council Regulation (EEC) No $793 / 93$ and Commission Regulation EC/1488/94 as well as Council Directive 76/769/EEC and Commission Directives 91/155/EEC, 93/67/EEC and 2000/21/EC. OJ L396/1, 30 December 2006.

European Commission, 2016. Options for the strategic approach to pharmaceuticals in the environment. Task $1 \mathrm{Re}-$ port. Available from: https://ec.europa.eu/info/sites/info /files/study_report_public_consultation_pharmaceuticals_ environment.pdf

Escher BI, Hermens JLM, 2002. Modes of action in ecotoxicology: Their role in body burdens, species sensitivity, QSARs, and mixture effects. Environ. Sci. Technol. 36:201-4217.

Farré ML, García MJ, Tirapu L, Ginebreda A, Barceló D, 2001. Wastewater toxicity screening of non-ionic surfactants by Toxalert ${ }^{\circledR}$ and Microtox ${ }^{\circledR}$ bioluminescence inhibition assays. Anal. Chim. Acta. 427:181-189.

Fent K, 1996. Organotin compounds in municipal wastewater and sewage sludge: contamination, fate in treatment process and ecotoxicological consequences. Sci. Total Environ. 185:151-159.

Ferrario C, Finizio A, Villa S, 2017. Legacy and emerging contaminants in meltwater of three Alpine glaciers. Sci. Total Environ. 574:350-357.

Ferrario C, Parolini M, De Felice B, Villa S, Finizio A, 2018. Linking sub-individual and supra-individual effects in Daphnia magna exposed to sub-lethal concentration of chlorpyrifos. Environ. Pollut. 235:411-418.

Gary MD, Gaddis M, Gaddis ML, 1990. Introduction to biostatistics: Part 4, statistical inference techniques in hypothesis testing. Ann. Emerg. Med. 19:820-825.

Gerhardt A, 1995. Monitoring behavioral responses to and ef- 
fects of metals in Gammarus pulex (Crustacea) with impedance conversion. Environ. Sci. Pollut. Res. 2:15-23.

Gerhardt A, 2007. Aquatic behavioral ecotoxicology - prospects and limitations. Hum. Ecol. Risk Assess. An Int. J. 13: 481-491.

Häder DP, Erzinger GS, 2017a. Arsenic pollution measured with an online monitoring system using Daphnia. Open J. Environ. Biol. 1:027-034.

Häder DP, Erzinger GS, 2017b. Daphniatox - Online monitoring of aquatic pollution and toxic substances. Chemosphere 167:228-235.

Hellou J, Cheeseman K, Desnoyers E, Johnston D, Jouvenelle ML, Leonard J, Robertson S, Walker P, 2008. A non-lethal chemically based approach to investigate the quality of harbour sediments. Sci. Total Environ. 389:178-187.

Hendriks AJ. Stouten MDA, 1993. Monitoring the response of microcontaminants by dynamic Daphnia magna and Leuciscus idus assays in the Rhine delta: biological early warning as a useful supplement. Ecotoxicol. Environ. Saf. 26:265-279.

Husson SJ, Costa WS, Schmitt C, Gottschalk A, 2012. Keeping track of worm trackers. WormBook 22:1-17. doi/10.1895/ wormbook.1.156.1.

Jeong JH, Kim JH, Lee BC, Kim SD, 2008. Development of a new biomonitoring method to detect the abnormal activity of Daphnia magna using automated grid counter device. Sci. Total Environ. 389:545-556.

Jeong TY, Jeon J, Kim SD, 2014. Development and evaluation of new behavioral indexes for a biological early warning system using Daphnia magna. Drink. Water Eng. Sci. 7:1-9.

Kaul S, 1993. The importance of biotope mapping for nature conservation in India. In: A.K. Tripathi, AK. Srivastava and S.N. Pandey (eds.), Advances in environmental sciences. Ashish Publishing House, New Delhi.

Koçbaş F, Oral R, 2015. Daphnia magna as a test species for toxicity evaluation of municipal wastewater treatment plant effluents on freshwater cladoceran in Turkey. Turk. J. Fish Aquat. Sci. 15:619-624.

Lencioni V, 2018. Glacial influence and macroinvertebrate biodiversity under climate change: lesson from the Southern Alps. Sci. Total Environ. 622-623:563-575.

Lencioni V, Grazioli V, Rossaro B, Bernabò P, 2016. Gene expression profiling of responses induced by pesticides employed in organic agriculture in a wild population of the midge Chironomus riparius. Sci. Total Environ. 557-558: 183-191.

Lencioni V, Marziali L, Rossaro B, 2012. Chironomids as bioindicators of environmental quality in mountain springs. Freshw. Sci. 31:525-541.

Lindqvist N, Tuhkanen T, Kronberg L, 2005. Occurrence of acidic pharmaceuticals in raw and treated sewages and in receiving waters. Water Res. 39:2219-2228.

Lishman L, Smyth SA, Sarafin K, Kleywegt S, Toito J, Peart T, Lee B, Servos M, Beland M, Seto P, 2006. Occurrence and reductions of pharmaceuticals and personal care products and estrogens by municipal wastewater treatment plants in Ontario, Canada. Sci. Total Environ. 367:544-558.

Maltby L, Blake N, Brock TCM, Van Den Brink PJ, 2005. Insecticide species sensitivity distributions: Importance of test species selection and relevance to aquatic ecosystems. Environ. Toxicol. Chem. 24:379-388.
Mandaric L, Diamantini E, Stella E, Cano-Paoli K, Valle-Sistac J, Molins-Delgado D, Bellin A, Chiogna G, Majone B, DiazCruz MS, Sabater S, Barcelo D, Petrovic M, 2017. Contamination sources and distribution patterns of pharmaceuticals and personal care products in Alpine rivers strongly affected by tourism. Sci. Total Environ. 590-591:484-494.

Morselli M, Vitale CM, Ippolito A, Villa S, Giacchini R, Vighi M, 2018. Predicting pesticide fate in small cultivated mountain watersheds using the DynAPlus model: Toward improved assessment of peak exposure Sci. Total Environ. 615: 07-318.

Movahedian H, Bina B, Asghari GH, 2005. Toxicity evaluation of wastewater treatment plant effluents using Daphnia magna. Iranian J. Environ. Health Sci. Eng. 2:1-4.

Niedrist GH, Füreder L, 2016. Towards a definition of environmental niches in alpine streams by employing chironomid species preferences. Hydrobiologia 781:143-160.

Nyman AM, Schirmer K, Ashauer R, 2014. Importance of toxicokinetics for interspecies variation in sensitivity to chemicals. Environ. Sci. Technol. 48:5946-5954.

OECD Guidelines for the Testing of Chemicals, Guideline 202: "Daphnia sp., Acute Immobilisation Test" adopted April 2004.

OECD Guidelines for the Testing of Chemicals, Guideline 211: “Daphnia magna Reproduction Test” adopted October 2012.

R Development Core Team, 2017. R: A language and environment for statistical computing. the R Foundation for Statistical Computing. Vienna. Available from: http://www.R-project.org/

Reichmuth JM, Roudez R, Glover T, Weis JS, 2009. Differences in prey capture behavior in populations of blue crab (Callinectes sapidus Rathbun) from contaminated and clean estuaries in New Jersey. Estuar. an Coast. 32:298-308.

Reid G, McG, Mac Beath T, Contreras CK, 2013. Global challenges in freshwater-fish conservation related to public aquariums and the aquarium industry. Int. Zoo Yb. 47:6-45.

Rico A, Van Den Brink PJ, 2015. Evaluating aquatic invertebrate vulnerability to insecticides based on intrinsic sensitivity, biological traits, and toxic mode of action. Environ. Toxicol. Chem. 34:1907-1917.

Rossaro B, Lencioni V, 2015. A key to larvae of species belonging to the genus Diamesa from Alps and Apennines (Italy). Eur. J. Environ. Sci. 5:62-79.

Rubach MN, Baird DJ, Van Den Brink PJ, 2010. A new method for ranking mode-specific sensitivity of freshwater arthropods to insecticides and its relationship to biological traits. Environ. Toxicol. Chem. 29:476-487.

Selvaraj V, Santhakumar K, 2017. Analyzing locomotor activity in Zebrafish larvae using wrMTrck. Zebrafish 14:287-291.

Sun J, Quan Y, Wang W, Zheng S. Liu X, 2015. Potential contribution of inorganic ions to whole effluent acute toxicity and genotoxicity during sewage tertiary treatment. J. Hazard. Mater. 295:22-28.

Tchobanoglous G, Burton FLH, Stensel D, 2003. Wastewater engineering, treatment and reuse. McGraw-Hill Education: $1819 \mathrm{pp}$.

Teodorović I, Bečelić M, Planojević I, Ivančev-Tumbas I, Dalmacija B, 2009. The relationship between whole effluent toxicity (WET) and chemical-based effluent quality assessment in Vojvodina (Serbia). Environ. Monit. Assess. 158:381-392. 
Tyagi VK, Chopra AK, Durpagal NC, Arvin K, 2007. Evaluation of Daphnia magna as an indicator of toxicity and treatment efficacy of Municipal Sewage Treatment Plant. J. Appl. Sci. Environ. Mgt. 11:61-67.

Untersteiner H, Kahapka J, Kaiser H, 2003. Behavioural response of the cladoceran Daphnia magna STRAUS to sublethal copper stress - validation by image analysis. Aquat. Toxicol. 65:435-442.

Villa S, Di Nica V, Tanita P, Bellamoli F, Miari F, Finizio A, Lencioni V, 2018. Comparison of the behavioural effects of pharmaceuticals and pesticides on Diamesa zernyi larvae (Chironomidae). Environ. Pollut. 238:130-139.

Villa S, Vighi M, Finizio A, 2014. Theoretical and experimental evidences of medium range atmospheric transport processes of polycyclic musk fragrances. Sci. Tot. Environ. 481:27-34.

Wiberg-Larsen P, Graeber D, Kristensen EA, Baattrup-Pedersen A, Friberg N, Rasmussen JJ, 2016. Trait characteristics determine pyrethroid sensitivity in nonstandard test species of freshwater macroinvertebrates: a reality check. Environ. Sci. Technol. 50:4971-4978.

Wolf NG, Swift PR, Carey FG, 1988. Swimming muscle helps warm the brain of lamnid sharks. J Comp. Physiol. B. 157:709-715.

Wogram J, Liess M, 2001. Rank ordering of macroinvertebrate species sensitivity to toxic compounds by comparison with that of Daphnia magna. Bull. Environ. Contam. Toxicol. 67:360-367. 